\title{
Transnational corporations, labour relations and trade unions - the case of Russia
}

\begin{abstract}
This article looks at the relationships between trade unions and transnational companies, using a series of case studies into actual trade union practice in enterprises and looking at the level of adaptation both of 'old' as well as 'new' trade union organisations. The author's theme is how the range of new intra-organisational practices introduced by new owners influence the position of workers and of trade union participation in the regulation of labour relations, from the perspective of the extent to which these aggravate contradictions in the labour sphere. The operation of collective agreements is evaluated and the social role of trade unions in enterprises in practice is identified. The author concludes with a look at how trade unions in Russia are structured and at their relationships with members, as well as at the impact on their activities, both amongst the traditional and amongst the alternative trade union structures, of the arrival of transnational companies in the country - an event which has had unexpectedly positive results for trade union organisations.
\end{abstract}

Keywords: transition, transnational corporations, trade unions, labour relations, new management techniques, trade union organisation, collective agreements, functions of trade unions, alternative union structures, industrial conflict, international unions

\section{Introduction}

Over the last twenty years, the economy has undergone significant changes connected with globalisation and the growing role of transnational corporations (TNCs). ${ }^{1}$ The key mechanism in the process of globalisation regarding national labour markets is the so-called 'social dumping', by means of which TNCs receive advantages, concentrating particular production in countries with low wages. Using the labour of different countries, TNCs articulate a universal demand and, thus, play an important role in the internationalisation of the labour market. In the sphere of the organisation of work, TNCs operate on the principle of 'the transmission belt', introducing their business practices into the economy that, in turn, influence the standards and system of regulation of labour relations.

1 A TNC is a particular form of the organisation of the economic activities of a firm based on the labour co-operation of the workers of enterprises located in different countries of the world and incorporated by a uniform ownership of the property-based means of production. Specialists of the United Nations consider a TNC to be any company having capacities abroad. This article will be concerned, basically, with western corporations which have entered the Russian market. 
Many publications are devoted to the problem of relations between transnational companies and the trade union movement, but most are more ideological than analytical. The majority of trade union specialists in the sphere of labour relations emphasise the anti-social character of globalisation, frightening us with the gloomy prospects for Russians of integration into a global economy where the authority of the employer is boundless. For Russia and the CIS countries, where new international tendencies have coincided in time with the transition from a planned economy, these changes can be rather fundamental. The best way to evaluate this is by observing new tendencies at the moment of their origin, at the level of the direct interaction between workers, trade unions and employers, that is at the level of the enterprise. In this article, based on materials of the research project devoted to studying actual trade union practice in enterprises, ${ }^{2}$ a generalised analysis of the adaptation of the Russian 'old' (traditional) and 'new (alternative) trade unions to working with corporations is offered. The focus of attention is the question of how intra-organisational processes initiated by new owners are reflected in the position of workers and in trade union participation in the regulation of labour relations.

\section{'The culture of Pepsi-Cola' against the 'culture of methylated spirits'}

At the present moment, according to specialist estimates, some $400 \mathrm{TNCs}$, having about 1300 enterprises, operate in CIS countries. When TNCs first came to Russia, expectations were quite optimistic: investments and, with them, new technologies would at last appear; working conditions would improve; and new jobs would be created. In the mass consciousness there was a fairly idealised image of work in transnational companies: when foreign corporations hired workers for their enterprises, competition was such as for a prestigious university. For example, when the Ford car assembly enterprise opened, about ten thousand people applied for four hundred jobs. These days, however, work in a TNC does not seem such an attractive prospect:

Earlier selection was more tough. Now everyone already knows that pay here is ten thousand, but it is necessary to work hard. People are not in such a hurry.

People, despite pretty good earnings, find it difficult to get used to new working conditions: to the strict hierarchical order; the intensification of work; the toughening of disciplinary demands; the achievement of production targets; quality of production; and the constant threat of redundancy. To put it briefly, the Russian system of work organisation allowed for variability - it is possible to work less and to receive less but the new system excludes it practically completely. We shall try to characterise briefly those intra-organisational changes in the system of work which have been brought with new management.

2 Research project Post-Socialist Trade Unions, Low Pay and Decent Work: Russia, China and Vietnam, 2005-2007 under the direction of Professor S. Clarke (Warwick University), with the support of the ESRC. The Russian part of the research was carried out by the Institute of Comparative Labour Relations Research (ISITO) and included the conduct of thirty case studies of trade union organisations. 
The arrival of a foreign owner causes plenty of changes in the internal environment of the enterprise, the impact of which is quite positive. Investments in production increase the technical capacity of the enterprise and modernise the equipment. The introduction of international standards of industrial activity and corporate management are accompanied by the centralised standardisation of business processes; production discipline and health and safety become stronger; and working conditions improve. People are dressed in brand new work clothes; equipped with means of individual protection; and they work in repaired or reconstructed shops where there are no dirty corners and no place to sit around getting drunk. In the organisation of work, the key aspect is the strengthening of control over production that has put an end to the autonomy of workers in their workplaces and has led to a reduction in the authority of line managers - important characteristics of the pre-reform system of the organisation of production (Clarke, 1999).

\section{Payment and work intensity}

Changes have also affected systems of payment. First, a significant differentiation of wages between groups of workers has been established. The work of specialists, and especially managers, is evaluated much higher than the work of workers. Second, new systems of payment are based on an increase in the rate for the job and a significant reduction of the system of bonus payments (the low level of the rate in the Russian piece rate-bonus system for the payment of workers was transformed from a system of bonuses into a system of penal sanctions). Work which does not provide any bonus for achieving and over-achieving the plan seems unnatural to Russian workers. At one of the enterprises included in the research, the reaction of workers to the new system of payment reminded one of the Taylorist 'phenomenon of loafing':

And he comes to work and knows that whether he works furiously or slackly, he will receive $80 \%$ all the same. He has come, he is paid. ${ }^{3}$

However, management usually quickly establishes control over working hours and those performance standards which force workers to work at full capacity. In general, the duration of working hours for workers is normalised (overtime becomes less) but, simultaneously, this has an impact on the possibility to earn. If there is no overtime, the intensity of work of workers who want to earn more has reached its physical limit:

To earn, people live at the factory: they spend the week producing; on Saturday they leave. The conveyor machine squeezes everything out. Some people are pleased, stupid people, that there is an opportunity to earn. Yes, there is, but that is not the point: what are you doing to your health for these three thousand extra?

3 In this article, the direct quotes are taken from interviews with workers, trade union leaders and managers of the investigated Russian enterprises of three corporations: Alcoa-Russia (author of the case study: L. Cheglakova); Ford Motor Co (author of the case study - V. Ilyin); and TNCBP. According to arrangements made with the respondents, their position and place of work are not referred to. 
The high intensity of work in the factories of transnational corporations forces out the older generation of workers as performance standards and standards of work are designed for healthy, young people. At the same time, retirement on a pension for ordinary Russians, if they are not a state employee or a deputy, as is well-known, is a step into poverty. Therefore, they work 'to the end' and practically until they are 'worn out'.

There is one more no less prominent aspect - the increase in the intensity of work of managers and specialists. The transition to new systems of payment directly stimulates personnel to the improvement of their professional skills, their grade and the increase of their educational level, since increasing qualifications and the level of professional training is one of the criteria for increasing wages. By and large, this represents, certainly, a positive tendency. However, in many enterprises this stimulating mechanism turns out to be 'superfluously effective'. Managers and specialists at all levels in drawing up their individual plans voluntarily incur the maximum obligations as all of them are taken into account in the calculation of points on the basis of which the bonus is paid:

Managers and specialists are interested and motivated not simply in working their working hours, but in fulfilling all their obligations - for the content of their work and the tasks they set themselves.

The over-estimated obligations cannot be carried out during regular working hours. Overwork becomes a system, a way of life.

\section{Social benefits}

An important element of labour relations is the granting to workers of additional benefits, services and social payments (the social package). Historically, the inherited Soviet practice of the granting of social services to workers was part of the system. A foreign owner, having bought the enterprise, tries as a rule not to break with tradition and, at that stage, measures significant to workers are kept. For workers who have often got tired of local charlatans, the social policy of the foreign owner seems more balanced, as well as being tolerant in relation to workers and their national mentality:

It became better. I do not want to say that the company 'Russian aluminium' is worse, but at least the Americans take a more human approach to such things as old age and war veterans than our Russian ones.

It is necessary to understand that, for the employer, this is not just charity - the implementation of social programmes provides advantages in the competition for labour and a kind of stimulus to productive work, as well as stabilising the social climate in the enterprise and assisting in the formation of a positive image of the company.

Thus, there has been a process of a modernisation of the policy of benefits. This has consisted of a gradual transition from the historically-developed model of collective benefits to a policy of individual benefits for workers chosen by the company. These 
benefits are no longer rights; they are personalised: that is, they are given to each worker separately and assume the use of the principles of the solidarity participation of workers in financing places for rest and sanatorium treatment, and in the provision of pensions and so forth. Simultaneously, benefits-in-kind are replaced by a standard set of monetary benefits. In the sphere of housing programmes, there is a transition from the traditional Soviet model, under which the enterprise provided the workers with housing through a queue, to a model of individual mortgage credit. There has also been a transition to insurance principles in the sphere of workers' health care, a transition to an individual share of workers in the corporate provision of pensions, etc. Accordingly, the majority of companies have refused to maintain the social and welfare apparatus as part of the company, selecting providers of social services on a competitive basis.

\section{Employment}

With a view to increasing the flexibility of working personnel and to lowering labour costs, company administrations have started actively to use contract labour. Recruiting agencies select workers for companies to carry out work on a temporary basis. According to the leaders of the trade union committee, they are paid almost twice as much as a permanent worker with similar qualifications. To tell the truth, these workers are hired on temporary contracts, do not receive medical insurance and do not participate in professional advancement connected with increasing salary associated with accessing higher grades. Neither can temporary workers join the trade union.

The basic schema is outsourcing - removing employees of non-core divisions from the staff of the enterprise and simultaneously creating new market structures on the principles of 'business to business' services. Moreover, they are actively introducing personnel leasing schemes: some workers are removed from the staff and transferred to a personnel agency which formally becomes their employer but, in fact, they continue to work in their former company (out-staffing). This is a world-wide trend - in global practice, more and more well-known and profitable companies prefer not to burden themselves with personnel as a result of the creation of 'weightless' corporations which have almost completely liquidated their own production.

The exit of large companies from the labour market results in a real reduction in permanent jobs. In Russia, employment in the largest companies increasingly ceases to be stable and workers lose their feelings of security and stability. This entails serious problems, above all by way of a reduction in the motivation and loyalty of the personnel. In fact, it is impossible to dismiss the social motives for work which can be characterised by a psychological attachment to the labour collective - or, in other words, the attraction of a social network. Each person from the non-staff body subconsciously does not perceive the company which is the actual employer as his or her own. And this breaks the carefully imparted corporate spirit. The result is that employees do not necessarily work in a detached way, but certainly not with the zeal favoured by the employer.

It seems that within the change in the structure of employment is concealed a certain contradiction between the interests of shareholders and the interests of hired managers. Shareholders are interested in the reduction of costs through changes in the structure of expenditure (accounts with an agency come under the heading of business development). However, for direct heads the removal of personnel from the staff significantly 
complicates the management of labour because any manager wants to deal with a person whose behaviour is predictable and who is easily incorporated into the existing social structure.

\section{Corporate culture}

Transnational companies offer an attractive model of corporate solidarity within the framework of which the common interests of the owner, managers and workers in the competitive struggle of the corporation stand in the foreground. However, when high levels of intensity and a strict work regime are not compensated by high payment, the cultivation of the idea of corporate solidarity and all the corresponding rhetoric 'the purpose of the company', 'the mission of the company', 'the values of the company' - only irritate Russian workers:

Understand that western companies coming here try to veil all this as team work: 'we are members of one team' ... Come on! They operate with slogans, the same as in McDonald's: 'You know, we do not pay you a fig, but all of you are members of one team, the McDonald's team!' Everywhere is the same. But, while in McDonald's they are young boys and girls, here already everywhere are adult people and these slogans are good only at first, when you have got into the western company and are glad; 'Well, they were not here earlier and now they are, and I am with them, and we are all members of one team' ... After a while, you come to see that all this is only words not to pay money.

The consequences of the introduction of international standards in production and management are the aggravation of contradictions in the labour sphere of the enterprise: between the new demands and established labour practices; the conflict between labour cultures; and the increase of expectations from the trade unions.

\section{Uniform company - uniform trade union}

Reform of the management of the enterprise is accompanied by the re-organisation of the interaction between the company and the trade union. For local trade union organisations, the problem of the mutual relationships between the elected trade union body and the owners (the managing company) is becoming increasingly urgent. On the owner depends today not only the level of pay, but also the contents of the social package and other major aspects of the regulation of social-labour relations. The difficulty is that the real interaction between trade unions and the owner, and the state of social-partner relations, are extremely complicated - the legislation focuses trade unions on mutual relations with the representatives of the employer at the level of the enterprise (the director of the enterprise, the deputy director for personnel management, etc.), who are objectively limited in their competences (everything is resolved at higher levels).

For local trade union organisations, this means an obvious narrowing of their activity as they can conduct real dialogue only at the level of the managing company, instead of at the enterprise level (with these latter being more and more reduced to production platforms). In this sense, the most urgent problem for primary trade union organisations becomes the search for mechanisms of constructive interaction with the 
representative of the owner at the level of the managing company. This, in turn, demands the association of efforts and, therefore, the establishment of direct horizontal connections between trade union organisations of the different enterprises included in the corporation. The principle of the construction of Russian trade unions is industrialterritorial, but the changed structure of management (the formation of vertically-integrated companies) dictates the need to search for new forms of trade union interaction with which more effectively to conduct social dialogue with employers at the top echelons of corporations.

One such form is the co-ordinating council of trade union organisations within a corporation. An example is the Co-ordinating Council of Trade Unions of the Belokalitvenskii Combine and the Samara Metal Works - Russian enterprises which are included in the Alcoa-Russia corporation. ${ }^{4}$ The Council meets several times a year. Association of effort takes the form of the swapping of information through an exchange of effective techniques and methods. Meanwhile, industry differences and, correspondingly, distinctions in the resources and tasks of the sectoral trade union associations, to which the local organisations belong, create certain problems for solidarity between trade unions. ${ }^{5}$ In particular, this impedes them from uniting behind the issues facing the factory organisations.

Besides this, the difficulties in the presentation of identical demands to an employer are connected with differences in the standard of living and the situation on the local labour markets in the different regions of Russia. Belokalitva, for example, is a citydominating enterprise: there are practically no other enterprises in the city demanding labour with the same level of education and training. The Samara Metal Works is one of many industrial enterprises in Samara competing for labour with other large industrial enterprises:

There, the subsistence minimum is less and job rates different; therefore, it is impossible to compare our salary and theirs. They complain that wages are so high at the Samara Metal works, but we ... We went there, and life is cheaper there. They have one factory in the city, but here it is difficult to keep workers.

Therefore, even where some issues are held in common - for example, timeliness of the payment of wages, questions concerning indexation and the increase of pay, subsidies for meals, and so forth - it is nevertheless impossible to consolidate actions on the question of the size of wages (Cheglakova, 2008).

To increase the status of the negotiating process, one practice that can be used is to transfer powers to negotiate with the management of the company to the relevant industrial trade association, as has been done in Russian Aluminium, where these powers were transferred by the co-ordinating council to the Central Council of the MiningMetallurgical Trade Union of Russia.

4 Such a practice is not unique - similar co-ordination councils have been created in many Russian enterprises, including the corporations JTI (Gallagher); RUSAL; Eurocement; etc.

5 The trade union organisation of the Belokalitvensk combine is part of the Federation of Workers in the Aviation Industry, while SMZ is part of the Mining-Metallurgical Trade Union of Russia. 
The creation of trade union co-ordinating bodies frequently demands considerable organisational effort, not only in the sense of overcoming the sectoral and regional differences of interest of the local organisations, but also in that of overcoming the resistance of company administrations which, naturally, are not interested in any solidarity trade union actions taking place within their enterprises. At the same time, the Russian part of company management has still not quite left behind the traditional idea of the role of trade unions in the organisation of the labour sphere. Their expectations of trade unions can encourage the administration itself to act as the initiator of such an association, believing that it can promote both an improvement of the climate and a strengthening of trust in the collective, and to increase control over workers.

Such an initiative was shown in particular in the corporation TNK-BP (concerning the Russian part of its top management). The Corporate Co-ordinating Council which has been created includes, on an equal footing, representatives of management and the chairs of the united regional trade union committees and of the trade union committees within the companies making up the group. In the regions, there are regional co-ordinating councils, whose members are the directors of the branches, the heads of enterprises and the representatives of the trade unions of subsidiaries within the company. At its meetings are considered social-labour questions demanding joint consideration in terms of the subsequent formation of company policy on them.

It is necessary to note that, in spite of it being an initiative and resource of the employer, rather than the trade union, the creation of such negotiating platforms has a significant influence on the position of trade union organisations. First of all, trade unions have found their own channel of dialogue with the management of the company

The opportunity to take local problems directly up to the management of the company has appeared, without risking losing half the information through the hierarchy.

Second, trade unions have gained direct access to information on impending changes in the companies as well as the opportunity of inclusion in the reforms being carried out. Finally, the problem of the lack of dialogue and the exchange of information between the trade union leaders of enterprises in different regions has, to a certain extent, been resolved.

The most radical form is the re-organisation of the trade union structure and the creation of corporate trade unions - inter-regional, or even international, trade union organisations uniting and consolidating the actions of the local trade union organisations of enterprises which are included within the uniform corporation. An example of such a vertically-organised trade union is the international association of trade union organisations (MOPO) of LUKOIL. ${ }^{6}$ Many Russian companies have willingly introduced such re-organisations (Gazprom, Sibur, and so forth).

6 It includes 364 local and about thirty unified trade union organisations of affiliates of the company in 25 regions of the Russian Federation, as well as in Azerbaijan, Ukraine, Bulgaria, Romania and Moldova (almost 170000 people). 


\section{Collective agreement regulation}

One of the most effective forms of the interaction between employers and trade unions is joint work on the preparation and conclusion, and later the implementation, of collective agreements. Contemporary Russian labour legislation, adapted to a market-based system of relations, contains only the most minimal social guarantees for workers and directs the parties to labour relations (employers and workers) towards contractual regulation. In this connection, the role of collective agreements as the basic local legal act in the working environment, together with the role of trade unions as the authorised representatives of the social-labour interests of workers, is essentially growing: it is necessary for the collective to live and work with what it is possible for the trade unions to agree with the employer. But, in a transnational company, the traditional practice of a collective agreement 'does not work' - there is practically nothing to agree - while the overwhelming majority of proposals cannot be considered at the level of the enterprise since the decision on these questions is within the competence of the head office of the company:

All the expenditure on our collective agreement is included in the business plan. During the preparation of the business plan, we calculate our 'little wishes'; we send everything to the company and they decide what to do with it. When we prepare proposals, we base ourselves on the figures of the last year - how much help we allocate, how much we spend on [medical] treatment; we look at what actions we need and we calculate. The basic document in the company, all the same, is the business plan. If there is no money in the business plan, you can imagine what use is the collective agreement.

Both trade unions and the heads of enterprises understand this - if problems are not resolved, it is not the fault of the trade unions or even the administration, but of the centre -

$\mathrm{He}$ (the director of the enterprise) understands everything and is glad to meet the wishes of the workers, but 'above' do not allow it.

The expediency of the conclusion of a collective agreement at the level of the uniform employer is obvious from the existence of a rigid vertical management structure. Moreover, the introduction of a uniform approach and unified social-labour guarantees for workers in all the enterprises of the company leads to the creation and introduction of general collective agreement standards.

Where there is a uniform inter-regional trade union organisation, it is possible to conclude a uniform general collective agreement such as, for example, in Gazprom or on the Russian railways. This is applied to all enterprises in the holding company, which is quite logical and, as a whole, does not break contractual principles: the local trade union organisations delegate the representation of the interests of workers, and the right to sign such a general contract, to the unified elected body of the trade union organisation of the company. In practice, this is frequently prevented by an important circumstance: the companies represent a more or less integrated organism, but the position 
of their subsidiaries may be very different (regional features and profits, on the size of which depends the financing of the collective agreement).

In such conditions, it is possible to prepare a framework document based on average parameters and, on the basis of such a document, to conclude a general agreement between the employer and the trade union association. The mechanism of contractual regulation in LUKOIL, for example, is defined by the principle: collective agreements should contain parameters for the social protection of workers which are not lower than those established in the Agreement. Each new Agreement, operative for three years, should, in principle, be higher in the level of interaction and, especially importantly, the scale of the obligations of the employer.

In a situation where the local trade union organisations of enterprises encompassed by the company belong to different sectoral trade unions and there is no unified representative trade union body - and, hence, it is impossible to conclude a general contract or agreement - there are other methods of the unification of collective agreements. In TNK-BP, for example, on the initiative and by the efforts of the administration (the corporate centre) a so-called standard (model) collective agreement has been developed. The model collective agreement has recommendatory status and its developers consider the basic applicability of this document to be a fair increase on the level of social guarantees up to 'a uniform level'.

However, analysis of the practice of the conclusion of collective agreements developed in recent years in the enterprises of the company allows us to conclude that the preparation of the contents of these legal acts occurs not independently by the parties but is actually little more than the registration of the social programmes authorised by the corporate centre. Additions and specifications are allowed only to a minimal degree, according to the financial possibilities of the enterprise (and which are gradually minimised by the centre). For the less successful enterprises in the holding company, inclusion in the collective agreements of the standard items of the model contract can be perceived as a blessing, as the level of the social security of workers is increased up to corporate standards (though this is still not always possible because of financial difficulties and restrictions). At the same time, for enterprises with traditions of wide social support of workers, it results in a reduction of the habitual benefits which is perceived painfully, even in spite of these being replaced with other benefits.

Representatives of the employer and the trade unions recognise that they are not free, in practice, to define the set and volume of social services included in the collective agreement. If it is possible to defend social positions so that they are, as a rule, included in the draft of the business plan, this is perceived as a joint victory of the administration and the trade union. The content of collective agreements is strictly supervised by the company and no local 'spontaneous action' is allowed:

Social policy and the key parameters of the collective agreement are developed at the head office in Moscow. At the enterprise, we can put forward proposals, but nothing in it can really change, if it is not decided in Moscow and is not included in the business plan. We constantly 
entered the indexation of salary in the corresponding section of the draft of the collective agreement, but the company also constantly deleted this item. ${ }^{7}$

Thus, the field for the negotiating process between the trade union and the representatives of the employer is limited. Collective agreements are, in most cases, a reproduction of corporate social standards, and the regulation of collective agreements, as the most effective mechanism of the regulation of social problems, practically does not occur and, actually, is even blocked.

\section{Conductors of an alien policy}

As a rule, corporations develop those social programmes which correspond to traditional directions in the social support of workers but, as has already been said, the mechanisms of maintenance and the principles of the activity vary. In connection with the realisation of a centralised social policy and the monetisation of benefits, trade unions have lost a number of decision-making functions in the sphere of benefits and subsidies as well as in the direct distribution of social benefits. Trade unions are not involved in the development of the social programmes introduced in the enterprises. At the same time, however, trade unions are included, to some extent, in the implementation of these programmes since the social services of the enterprises are loaded with current work and the heads of these services see in the trade unions an assistant in their daily activity. This they value highly and would not like to lose.

The social development department, the personnel service and the trade union - we are like a single whole.

The most widespread form of the participation of trade unions in social policy is the propagation of social programmes among workers, in terms of the explanation of their substantive provisions and essence. In some cases, trade unions show their own initiative in involving workers, for example in new, and still obscure for Russian workers, pension schemes and in organising meetings of workers with banks which provide mortgage loans.

Another form of the participation of trade unions in the realisation of social programmes is work on social committees. The majority of enterprises have kept 'housing', 'permits', etc. committees, with the participation of trade union representatives, where both current issues (accounts, distribution, queues) and disputable issues - for example, where two workers apply simultaneously for one permit - are resolved. Sometimes, the representatives of trade unions are allowed to participate in committees evaluating tenders for the selection of suppliers for social services (sanatorium, medical health organisations, and so forth): tendering is also centralised.

In the social sphere, it is possible to attribute (or relate) the cultural actions willingly undertaken by companies within the framework of the formation of corporate culture

7 Under the law, the content of a collective agreement is determined by the parties, i.e. the administration and the trade unions in an enterprise, and any outside intervention, including from higher structures, is not allowed. 
as also being part of the activity of trade unions. It is necessary to note that it is precisely in these activities that trade unions are most actively included, i.e. those which look for opportunities to rent sports facilities, organise sports competitions, to become involved in the work of sports sections and circles, etc.

Providing material assistance, cultural improvements, sports work and so on are the directions of trade union work which are habitual and demanded by rank-and-file members of the trade union. Material assistance, for example, is a very important tool for the maintenance of the status of the trade union organisation, as members of the trade union perceive it as a 'grey cash department', a particular 'fund for help' in difficult life situations, guaranteed by their own trade union payments. But, if material assistance is, basically, provided via their own trade union contribution payments, the social package is formed and distributed practically without the participation of the trade unions.

In the view of workers, the trade union in many respects still remains that organisation which has a direct relationship with the distribution of social benefits and services. Thus, for trade unions the activity of participation in social policy, or the preservation of the visibility of such participation, is one of the basic conditions for the preservation of trade union membership.

\section{Trade unions as a 'school of capitalism'}

\section{Trade unions and the administration}

For traditional trade unions, the loss of some functions in the direct distribution of social benefits, as well as the difficulty of acquiring new skills for the effective representation of the interests of workers, determine that niche which they have occupied in TNC enterprises: trade unions have become quite an effective tool of the adaptation of foreign management to Russian norms of labour behaviour and labour relations. Such a trade union is useful to new owners as a feedback channel - trade unions stand closer to the worker; they are more trusted; and they can collect more information on the presence of particular problems:

People can say things to the trade union they will not say to the employers ... Thanks to the trade union, we find out about problems, imminent conflicts, long before the situation becomes critical. And the earlier you find out about a problem, the easier it is to solve it.

Management is ready to put resources into the organisation of and support for such a feedback channel in the form of the trade union bureaucracy - the chair of the trade union committee receives a salary from the employer, is integrated into the administrative 'top level' of the enterprise and participates in planning meetings and in the development of the business plan, which sets the framework for the social programmes which are then fixed in the collective agreement. In return, trade unions in enterprises are increasingly trying to fit themselves into this niche - proving a reliable 'transmitter' of finished products: on the one hand, intra-organisational reforms for workers; and, on the other, raising problems 'from the workplaces' to the management of the companies. The existence of a rather wide range of problems connected with new practices 
in the labour sphere determines a large field of action for trade unions. They are active, but only in those frameworks which are defined for them by management:

If the impression is created somewhere that the trade union wants to take too much on itself, it is incorrect. The trade union takes exactly as much and exactly what the administration is ready and wants to give it.

In the absence of unity among workers and trade unions, transnational companies, possessing a good information base and huge financial possibilities, are able easily to use trade unions for their own interests. A resource of the trade union as a public organisation is transformed into a resource of the administration, which uses it for the efficient control of personnel. This role is realised and willingly expressed by trade union leaders:

Trade unions act as cement between workers and employers. And personally, my task consists of supporting the image of the company among workers, explaining to them the policy of the company. In fact, it is much easier for the trade unions to make contact with the worker than for someone else, because we have informal relations with workers. Therefore, the role of trade unions cannot be underestimated.

\section{Workers and trade unions}

The organisational traditions of Russian trade unions refer to automatic trade union membership for practically all employees. The local trade union organisations, having gone through a mass outflow of members in the years of radical economic reforms, have now become stronger, as is confirmed by a rather high density figure that, in many respects, is a consequence of the positive changes in the social and economic position of workers, as a number of researchers in the labour sphere testify. Not ideological but mercantile reasons more often provide the occasion to leave - or, on the other hand, to promote people to join - a trade union:

I have left the trade union: it is necessary to pay dues and what does it give me? But my daughter has joined. She has an interest - she goes in for sports; the trade union pays.

However, such pragmatic motives have not yet become the reason for a mass exodus from union organisations.

The most noticeable tendency in trade union membership in Russian TNC enterprises is the resignation from the union of a significant part of the representatives of management who have special working conditions under contract with the companies. In the opinion of trade union leaders, such a mass outflow of administrative personnel is caused not so much by such workers seeing themselves as opposed to the trade union side of labour relations, but by their unwillingness to 'advertise' the size of their wages through the payment of membership dues. The majority of union leaders recognise that managers are a social group lost to the union: the efforts of the trade union to involve management in its structures are senseless and useless. Membership of the union does 
not really give them any advantages in using social benefits and guarantees in comparison with workers who do not belong to the trade union, as the collective agreement is applied to all workers.

Other than this, however, there are some skilled workers who have left who do not want to pay trade union dues 'for nothing'.

Taking into account such trends, trade unions in rich companies, for which membership dues are by no means the basic source of income, are ready to establish a fixed sum as the membership dues, independent of salary, or to fix this sum for each category of worker, depending on their experience in the trade union. For example, the primary organisation of SMZ (Alcoa-Russia) has sent such a proposal as an amendment to the Charter of the Mining-Metallurgical Trade Union of Russia, but:

The moral side of the case disturbs us

- the Vice-President of the trade union committee asserts (Cheglakova, 2008).

In concrete conflict situations arising in production, the trade union more often acts as a buffer between workers and the administration than an organisation which really protects labour rights, consciously narrowing the sphere of its competence. Today for workers, the problem of the inadequacy of the wage and its continuous depreciation as a result of the rising cost of living is very acute. The trade union shows a readiness to support workers in their demands for wage increases, but only as the transmitter of the mood of the workers; that is, in the form of a statement of the problem to the management of the company. For example, when the service enterprises of Nizhnevartovsk took the initiative to raise the question of a wage increase with the head office of TNK$\mathrm{BP}$, the trade union supported the demand. At that moment, a pre-strike situation had, in fact, developed but the trade union leaders categorically refused to qualify it as such:

26 chairmen of trade union committees have signed a letter declaring their readiness to start picketing. They were not prepared to declare a strike, as it was economically not favourable either to the company or for workers. They only mentioned the possibility of picketing, and that is not at all the same as a strike.

Positive trade union practice is connected with the more active protection of the individual civil and labour rights of workers. The narrowing of the field of collective solidarity actions has directed the resources of the trade union committee to the channel of the resolution of the widest spectrum of individual problems with which workers appeal to the trade union:

Workers come here with all problems: someone has been treated badly; someone has not paid everything due. 
Among the requests are appeals to draw up letters and court papers, or to prepare documents for the privatisation of a summer house or the sale of an apartment. For this purpose, the trade union organisations have established legal departments -

In the organising committee, we have opened free-of-charge legal consultation; we have specially taken lawyers onto the staff. In total over the year, there have been more than 100 requests not connected with production.

Thus, in the logic of these events, the trade union acts as a service organisation reacting to the potential inquiries of its clients.

On the whole, and despite significant changes in the labour sphere, the practice of the interaction of trade unions and workers in enterprises is, in many respects, characterised by the preservation of the basic traditions of trade union activity established during the pre-reform period. The reduction of influence and the replacement of trade unions in the sphere of operation of business are compensated for by an expansion of the circle of the servicing of the social needs of workers. This situation is reflected in workers' attitude to the trade union. The trade union is perceived as something foreign - not a voluntary association of workers of the enterprise for upholding their interests in the sphere of work and employment in negotiations with the employer, but an external body, and one that is far from being the strongest, which can help to assert workers' rights.

In spite of many workers considering that their interests in the enterprise are not protected, they do not aspire to participate actively in trade union work, seeing no sense in it. The result is, on the one hand, an accumulation of discontent while, on the other, the passivity of members of the trade union does not provide the ground for the promotion of new, more independent and authoritative leaders.

\section{Working for Ford - corporations and new trade unions}

The arrival of transnational corporations in Russia not only stirred the traditional trade unions to activity, but has also given an impulse to the alternative trade union movement which, after its rise at the end of the $80 \mathrm{~s}$ and the beginning of the $90 \mathrm{~s}$, went through a period of slowed-down development connected with numerous crises, internal conflicts and splits. However, in recent years the theme of alternative trade unions has again started to resonate - one-by-one, messages are emerging concerning the existence of new trade union organisations in enterprises created by transnational companies producing for the Russian domestic market. This is becoming a trend - trade union organisations are being created by the assemblers of foreign cars, by retail workers in supermarkets and even by bank clerks. The administrations of transnational companies certainly perceive it as unfriendly, but active attempts to counteract trade union activity do not occur very often - it is necessary to observe the rules of the game where the right to create a trade union is guaranteed by national legislation.

The new organisations are, as a rule, appearing on the initiative of those from below, i.e. by workers getting together to self-organise. These trade union organisations frequently arise on a wave of labour conflict while their leaders are radically inclined, so they do not receive the support of FNPR trade union organisations, which are invariably 
loyal to the authorities and employers. Consequently, they necessarily become independent, or join some alternative trade union association. These new trade unions do not stake too much on the classical circuit of negotiations but, to a greater extent, on attracting the protest potential of workers. It is remarkable that it is precisely the prosperous transnational enterprises, with by no means the lowest salaries in the sector, which have now become the basic centres of the strike movement. In the last eighteen months alone, there have been strikes in the Russian enterprises of Ford, Heineken, Avtovaz, Eurocement and RUSAL. In total, 35 strikes were recorded in 2007, not including other protest actions (pickets and meetings of oil workers and workers in the GM-AVTOVAZ enterprise, and so forth). To tell the truth, far from all of them can be called large, or especially successful. However, the success of even a few of them is inspirational:

If at Ford it was possible to get something, it means that it is also possible at other factories!

It is necessary to take into account that they are supported not by the national trade unions but by local activists in enterprises organised by the much more aggressive, alternative trade unions.

These industrial conflicts sharply differ from the strikes of the 80 s and 90 s which had a defensive character, based on demands to pay unpaid wages. Now the demands are different, featuring: wage increases; the stability of employment; and the independence of the trade union. The difference is also that these demonstrations are, as a rule, not politicised (demands do not go beyond the trade union framework), while the organisers of the protest actions are ready to enter negotiation and accept compromise proposals, and do not call for a new revolution. In the environment of oppositional, especially left-wing, parties and movements one can see an aspiration to join the working class movement, having given it ideological force, but the new wave of trade union leaders have similarly acquired the lessons of the last decades when the independence of the alternative trade unions from the state and FNPR made them an easy object for manipulation by external forces.

The growth in the influence of the new trade unions in foreign enterprises is, in our opinion, promoted by a number of circumstances. First, there is something to take from these owners - it is not for nothing that trade unions arise in the most successful corporations working in those spheres, where the gap between costs and profit is highest. Second, foreign owners have a propensity to observe the national legislation and corporate ethics - they value their international image highly and their concern for this undoubtedly promotes the resolution of problems. Finally, the new trade unions which have arisen in the Russian enterprises of TNCs are being created 'from below', on the initiative of workers. They are to a lesser degree burdened by the Soviet past, they are less bureaucratised and they lean on real member organisation supported by workers. All this gives the trade union a real chance successfully to assert the rights of workers.

The most vivid example of the activity of such a new trade union is certainly the organisation at the Ford factory. The trade union committee, through a constant informing of rank-and-file members on the condition of labour relations and on their 
activities, aspires to create a situation in which the initiative will come from below and the trade union committee will only have to organise workers to carry it out:

We have set things up so that people decide. I spend all day in the shop, I approach people, I show them the work schedule, I say what possible routes there are: we strike, or they sell this schedule $+30 \%$. Will that be enough for you? No. Will it be enough if they sell the schedule $+45 \%$ ? Yes, that's all, I shall not strike. Dialogue with people. And if they say, for example, $+70 \%$, but people are not satisfied, then yes, we shall lead, we shall go on strike. But the protest should be born from within. And in negotiations, they give us that - sign that and we say: no, we can not, we sound out the opinion of people and should agree everything with them.

This principle in the organisation of relations with the administration of the enterprise is especially important. The chair does not take on the functions of individual representation:

\begin{abstract}
We have taken as a rule for ourselves the principle of the Polish trade union 'Solidarity', where there is a rule not to meet management in private. Because they play such interesting games; they can compromise at any moment. Here it is important: if you are caught in a corridor and have discussed any question on the run with the heads, it is not terrible, but if you go to a meeting, you only go with someone else.
\end{abstract}

Consciousness of the need for solidarity actions grows out of the practice of dayto-day trade union work with other organisations. The experience of the Ford trade union organisation reflects these practices. From the moment of the re-organisation of the Ford trade union, it became a centre of gravity for those groups of workers who were trying to create independent local organisations in their enterprises. Trends in the association of trade unions of foreign companies for the transfer of experience and solidarity actions have poured out into new organisational forms. One example is the creation of the inter-regional trade union of workers in the motor industry, which includes representatives of the local trade union organisations of Ford, GM-Avtovaz, Skania-Peter and Aftoframos-Renault.

\title{
'Support the workers of the banana plantations of Ecuador!'
}

Being part of a transnational corporation expands the opportunities for information exchange and the formation of horizontal relations with trade unions of foreign enterprises. Support for related foreign and international trade union organisations creates additional opportunities for Russian trade unions working in TNCs.

Concerning international corporations, the majority of trade unions in foreign countries have taken considerably more radical positions than they have on other questions. The international trade unions see their task in relation to transnational companies as being to ensure that the process of globalisation does not lead to a reduction in social standards in those states which are exporters of capital and that it promotes an increase in those countries which are importers. The international trade union associations start from the position that it is only possible to resist the globalisation of capital by organising workers' solidarity on a global scale. In this sense, the problem of low pay in 
Russian Ford factories becomes quite obviously more of a problem for workers in western countries who have lost jobs where these have been transferred to those countries which have cheap labour. Therefore, support for the Russian trade unions on the part of international organisations is specifically not humanitarian help, but a rational form of the protection of the interests of their members (Kozina, 2007).

New trade unions actively use this solidarity resource, including themselves in the network of trade union activity at the global level. The concept of international solidarity, which was hackneyed in Soviet times, acquires a new meaning for them. The success of the sensational action at the Ford factory in Vsevolozhsk is connected in many respects with the support of colleagues from the international trade unions of Ford workers, who threw letters at the head office. The French trade unions acted similarly in the protection of the dismissed chair of the trade union committee of the Moscow hypermarket Ashan, having sent a declaration to the management of the main company. Old trade unions relate to such international solidarity with care. They willingly use opportunities for exchange and these give, certainly, a positive result:

I have found out for myself that we are lagging behind, in the level of our organisation, in terms of those requirements which the organisation demands from us. I have understood that we should work a lot with people.

This was the statement of the chair of the trade union committee of the Russian enterprise of the Alcoa corporation, concerning his trip to Montreal for an exchange experience. Nevertheless, the heads of the Russian trade union organisation refused the proposal of the Canadian trade union of the company to unite in efforts to pressurise the employer to increase wages. Having weighed all the pros and cons, they decided that the interests of the Canadian and Russian sides in this question did not coincide, above all because of a difference in the standard of living of workers. In contrast, a similar situation - a trip to Brazil for a seminar of Ford trade union activists and acquaintance with the work of the local trade union organisation - transformed a modest welder from Vsevolozhsk into a confident trade union boss:

There I have seen such a situation. The chief of a section approaches a worker and says: 'Come on!' - 'I am not obliged to do it. We should meet the trade union committee.' The chief at once says: 'Well. You should not do it.' This is an indicator! Security, both material and moral. I saw real trade union work. ... It became insulting for Russia. We are people, not some kind of monkey! ... I saw. It was insulting. It lit me up.

He had understood for the first time that the trade union could be not such as he saw in Russia, and he returned to Russia with ideas for the revival of a true trade union.

\section{Between corporate and class solidarity}

The process of globalisation is inevitable; it has both positive and negative sides and to brake it is objectively impossible. What was the strategy of the transnational companies yesterday will be the practice of the administrative personnel of national companies tomorrow - international examples of business dealings already become 
determinant in the comprehension of the priorities of management. Certainly, the purpose of the economic activities of TNCs is the maximum extraction of profit, including through the reduction of labour costs. A policy of generous wages and social programmes are an integral element of the strategy and tactics of management, primarily in labour motivation, where social factors are used to promote employees to work more effectively. The purpose is to induce the worker to work more intensively and productively, with maximum results.

However, it is impossible to ignore that the arrival of TNCs has caused many positive changes in Russian enterprises. Investments in production, the modernisation of equipment and the introduction of new technologies, in combination with a corporate philosophy and social policy, supersede thorny questions of labour relations, displacing the emphasis on the improvement of working conditions and the co-ordination of the interests of workers and the employer. For employees, work in such companies seriously expands their horizons. They receive an opportunity to compare working conditions, not only with what they work at and receive in the next enterprise, but also with operating conditions in other regions, in another country. Finally, it is necessary to recognise that the management of western companies frequently brings with it a culture of a respectful attitude to trade unions and an experience of quite civilised relations with them.

The somewhat unexpected conclusion thus follows that the arrival of TNCs in Russian enterprises has given a positive impulse to the implementation of the activity of trade unions. This activity is multifarious: for the traditional organisations, there is a strengthening of the position of the trade union in the form of the individual legal and economic protection of workers, the search for direct forms and mechanisms of interaction with the management of the enterprise, the expansion of the horizontal connections of trade unions inside the corporation and the strengthening of the exchange of information with trade unions of the various enterprises of the company as well as with workers in the enterprise. Simultaneously, it strengthens the bureaucratisation of the trade union organisation (strengthening the internal structure of the trade union organisation, creating internal resources for the strengthening of positions in dialogue with the employer and divorcing the trade union leadership from the mass of workers). For alternative trade unions, it means more favourable conditions for the creation of independent organisations and opportunities for the use of collective methods of upholding the labour rights of workers, including by the organisation of protest actions and via the resource of the solidarity support of the international trade unions.

The choice between class and corporate solidarity is the system of co-ordinates in which Russian trade unions are compelled to be guided. By virtue of many reasons, including historical, this choice is varied - for the majority of Russian enterprises, the critical point when the trade union can represent a real opponent for the company does not appear even in remote prospect. Consensus between the trade unions and the administration is reached due to the voluntary refusal of trade unions to resolve essential questions for workers, such as the size of the salary, job security and so forth; they do, however, take the opportunity more actively to carry out their social functions for workers, helping, as well as they can, to support a balance between social responsibility and the economic efficiency of the enterprises. 
For the new trade unions, it would be too optimistic to expect the rapid emergence of a true trade union movement in Russia. The emergence of new, fighting trade unions is a long-term trend but, for now, the alternative trade unions are not mass membership and unite a rather narrow layer of radically-inclined workers. Today, the viability and authority of the new trade unions can be guaranteed only by their true independence. Only in this case are they capable of acting as an independent force expressing the interests of the workers instead of the orders of the sponsors.

\section{References}

Cheglakova L (2008) 'The trade union in a transnational company (on the example of a metallurgical works)' Economic Sociology 9(2): pp. 46-55.

http://ecsoc.hse.ru/issues/2008-9-2/index.html

Clarke, S (1999) 'Class structure in Russia during the transition period' Rubez No. $10-11$.

Kozina, I (2007) 'Post-soviet trade unions' National Notes 36(3): pp. 94-108.

Sobolev, E (2007) Social-labour relations in Russian economics: interest conflict or looking for agreement? M: RAS Economics Institute. 